\title{
Estilo de Aprendizaje
}

El Modelo de Aprendizaje Experiencial (ELM), compuesto de cuatro elementos:

- La experiencia concreta,

- La observación y la reflexión sobre esa experiencia,

- La formación de conceptos abstractos basados en la reflexión,

- Pruebas de los nuevos conceptos.

Estos cuatro elementos son la esencia de una espiral de aprendizaje que puede comenzar con cualquiera de los cuatro elementos, pero por lo general comienza con una experiencia concreta. Su modelo fue desarrollado principalmente para la educación de adultos, pero ha encontrado amplias aplicaciones pedagógicas en la educación superior.

La rueda del aprendizaje de David Kolb distingue los estudiantes activos, reflexivos, teóricos, y prácticos.

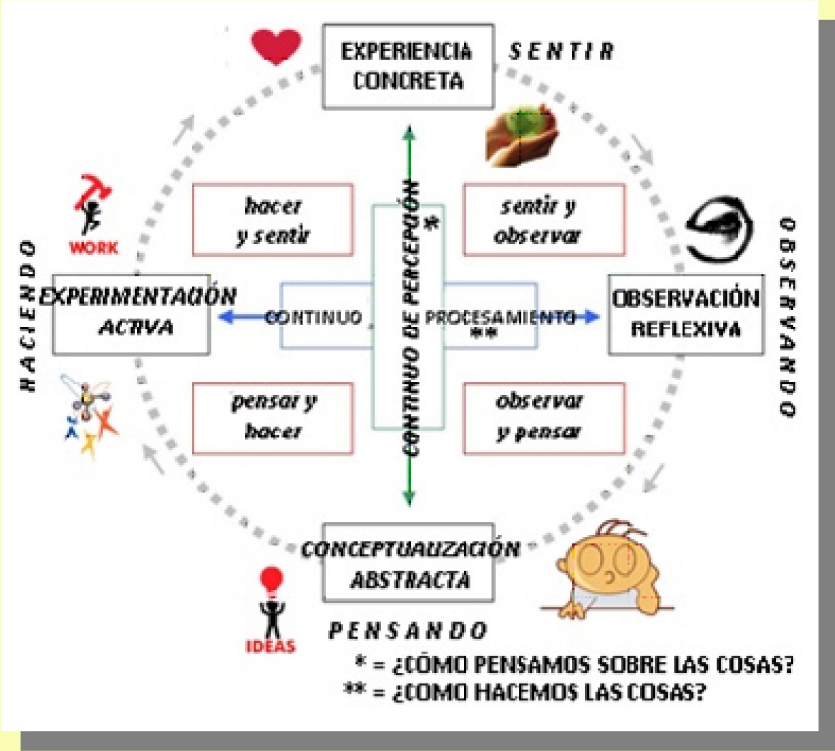




\section{Inteligencias Múltiples}

Howard Gardner, neuropsicólogo, es codirector del proyecto Zero en la Escuela Superior de Educación de Harvard, donde además se desempeña como docente de educación y de psicología, y como educador de Neurología en la Facultad de Medicina de Universidad de Boston.

Gardner señala las equivocaciones que se comete al describir a las personas como poseedoras de una única y cuantificable inteligencia, pues el ser humano tiene, por lo menos, ocho inteligencias diferentes, cada una desarrollada de modo y a un nivel particular.

Los programas de enseñanza sólo se basan en las inteligencias lingüística y matemática, dando una mínima importancia a las otras. Es por ello que, para lograr el objetivo de transformar a la institución educativa tradicional en una de Inteligencias Múltiples, se tiene que partir desde un trabajo en equipo en el que intervengan la escuela (docentes), y el hogar (los padres).

Al igual que hay muchos tipos de problemas que resolver, también hay muchos tipos de inteligencia. Hasta la fecha Howard Gardner y su equipo de la universidad de Harvard han identificado ocho tipos distintos: la Inteligencia Musical, Corporal-kinestésica, Lingüística, Lógico-matemática, Espacial, Interpersonal, Intrapersonal y Naturalista.

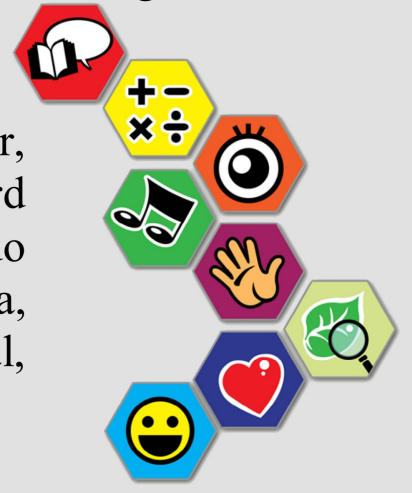

1. Inteligencia Lógica - matemática, la que utilizamos para resolver problemas de lógica y matemáticas. Es la inteligencia que tienen los científicos. Se corresponde con el modo de pensamiento del hemisferio lógico y con lo que nuestra cultura ha considerado siempre como la única inteligencia.

2. Inteligencia Lingüística, la que tienen los escritores, los poetas, los buenos redactores. Utiliza ambos hemisferios.

3. Inteligencia Espacial, consiste en formar un modelo mental del mundo en tres dimensiones, es la inteligencia que tienen los marineros, los ingenieros, los cirujanos, los escultores, los arquitectos, o los decoradores.

4. Inteligencia Musical es, naturalmente la de los cantantes, compositores, músicos, bailarines.

5. Inteligencia Corporal - kinestésica, o la capacidad de utilizar el propio cuerpo para realizar actividades o resolver problemas. Es la inteligencia de los deportistas, los artesanos, los cirujanos y los bailarines.

6. Inteligencia Intrapersonal, es la que nos permite entendernos a nosotros mismos. No está asociada a ninguna actividad concreta.

7. Inteligencia Interpersonal, la que nos permite entender a los demás, y la solemos encontrar en los buenos vendedores, políticos, profesores o terapeutas.

8. Inteligencia Naturalista, la que utilizamos cuando observamos y estudiamos la naturaleza. Es la que demuestran los biólogos o los herbolarios. 


\section{Hábitos de Estudio}

El desconocimiento de técnicas eficaz, para estudiar nos lleva a cometer graves errores, cuyo resultado la gran mayoría de las veces es una mala calificación. Aquí se te presentan los cinco errores más frecuentes:

1. Pretender aprender todo un día antes del examen.

2. Querer memorizar el contenido de los libros, sin comprender.

3. Estudiar acostado.

4. Faltar o no prestar atención a la clase.

5. Estudiar escuchando música a todo volumen.

\section{¿Qué son los hábitos?}

Un hábito es cualquier acto alcanzado por la experiencia y realizado regular y automáticamente. Es una práctica o costumbre que se realiza con frecuencia. Los antiguos filósofos decían que el hábito es una segunda naturaleza. Eso significa que la naturaleza del hombre se enriquece o empobrece, se perfecciona o se denigra, con el hábito.

Existen buenos y malos hábitos. Ejemplos muy sencillos, son: hábitos malos, fumar, comerse las uñas o dejar todo para después.

\section{BUENOS HÁBITOS DE ESTUDIO}

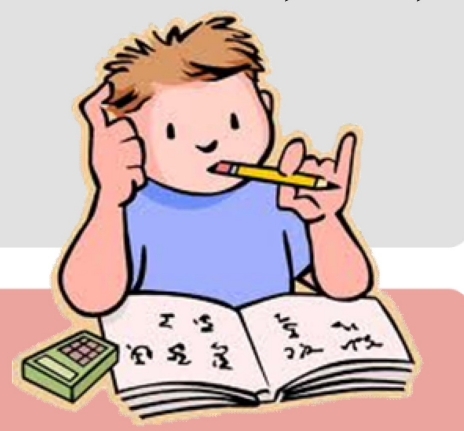

Se podría crear una lista considerable que contenga todos los hábitos de estudio recomendados por expertos en la materia, pero hoy nos vamos a centrar en los 5 hábitos que serán el comienzo de una nueva vida como estudiante y que harán la diferencia. Solamente se debe recordar que no bastará con que los conozcas. Los hábitos se adquieren a través de la repetición constante de los actos.

\section{Organiza el tiempo,}

2. Presta atención al docente,

3. Estudia todos los días,

4. Utiliza alguna técnica para estudiar,

5. Tener siempre una actitud positiva ante la vida. 